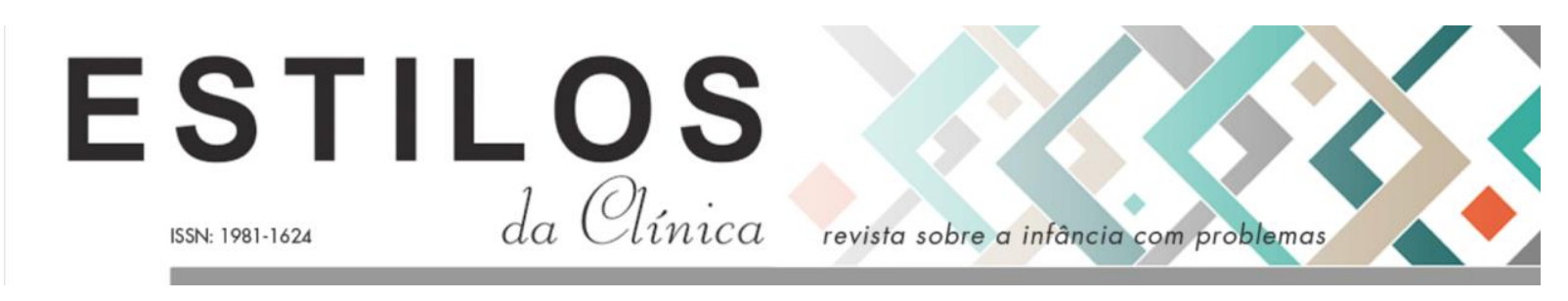

DOI: https://doi.org/10.11606/issn.1981-1624.v24i2p195-204.

Dossiê

\title{
A noção de defesa na teoria e na técnica de Sándor Ferenczi
}

\author{
Joselene Monteiro Silva; Laéria Bezerra Fontenele
}

Resumo. Analisamos, mediante revisão bibliográfica, o posicionamento de Sándor Ferenczi acerca da defesa, destacando o recalque, na teoria e na técnica psicanalítica, estabelecendo um contraponto com a obra freudiana. Evidenciamos que há estreita relação entre as tentativas clínicas - destacando a técnica ativa e a neocatarse - de contornar as limitações ao tratamento relativas aos mecanismos defensivos propostas pelo autor e sua forma de compreender o recalcamento. Por fim, formulamos uma crítica considerando as consequências das mudanças técnicas para o processo analítico: uma desvalorização da fala, o excesso de agressividade na relação transferencial e a localização do saber do lado do analista.

Palavras-chave: defesa; recalque; técnica psicanalítica; resistências.

\section{El tema de la defensa en la teoría y la técnica de Sándor Ferenczi}

Resumen. Partimos del análisis, mediante revisión bibliográfica, de la defensa en la obra de Ferenczi y sus implicaciones técnicas, estableciendo un contrapunto con la obra freudiana. Hay estrecha relación entre sus propuestas clínicas - con destaque para la técnica activa y la neocatarsis - en el intento de eludir las limitaciones al tratamiento relativas a los mecanismos defensivos y su forma de comprender el recalcamiento. Por último, formulamos una crítica considerando las consecuencias de los cambios técnicos para el proceso analítico: una desvalorización del discurso, el exceso de agresividad en la relación transferencial y la localización del saber del lado del analista.

Palabras clave: defensa; recalcamiento; técnica psicoanalítica; resistencia.

\section{Regarding the notion of defence in the theory and technique of Sándor Ferenczi}

\begin{abstract}
We made an bibliographic review of Sándor Ferenczi's work to analyse his position about the notion of defence, with emphasis in the repression and its technical implications, establishing a counterpoint with Freud's work. We noticed that there is a strong relation between his clinical proposals - among them the active technique and the neocatarse are the most rewardable - and his understanding of repression. Finally, we reviewed the consequences of the technical changes promoted by Ferenczi: an excess of aggressiveness in the transferential relation, a devaluation of the patient's speech and overvaluation of the analyst's knowledge.
\end{abstract}

1. Doutoranda do Programa de Pós-Graduação em Psicologia da Universidade Federal do Ceará, Fortaleza, CE, Brasil. E-mail: joselene.monteiro@gmail.com

2. Professora-Associada de Psicologia na Universidade Federal do Ceará, Fortaleza, CE, Brasil. E-mail: laeria@terra.com.br 
Keywords: defence; repression; psychoanalytical technique; resistance.

Sándor Ferenczi foi um dos discípulos preferidos de Freud, além de um clínico de grande talento, adepto da medicina social desde o início de sua carreira. Questões caras a Ferenczi, tais como o funcionamento do eu e dos sintomas, suas reflexões clínicas e propostas técnicas para enfrentar os obstáculos ao fim de análise, são atravessadas pela noção de defesa, objeto de nosso estudo.

\section{Sociedade e recalque: soluções e questões}

No primeiro momento de sua obra, a questão da pedagogia tem destaque para pensar uma profilaxia do adoecimento psíquico, pois ele considerava a pedagogia de sua época como um verdadeiro caldo de cultura das mais diversas neuroses (1908/2011, p. 39). O autor afirma que os neuróticos se defendem "de sua própria perversão inconsciente" (p. 42) e a sociedade, por sua vez, apenas dissimula, através da máscara de respeitabilidade, os pensamentos e tendências egoístas que condena em cada um de seus membros. Nesse sentido, a ele parece desejável considerar, com um objetivo profilático, a possibilidade de uma reforma pedagógica que permitiria prevenir evitar recalcamento de ideias (p. 42).

A psicanálise, segundo Ferenczi, mostra justamente que tal coerção social tem um preço alto, pois para manter suas tendências e desejos no inconsciente é preciso edificar organizações defensivas poderosas (1908/2011, p. 41). Nesse período, o autor acreditava que seria perfeitamente possível abandonar os princípios dogmáticos da sociedade em favor de uma compreensão dos motivos inconscientes de seus atos e sintomas, pois torná-los conscientes implicaria também um controle de tais impulsos, tornando o homem mais tolerante e a sociedade mais harmoniosa. Para Ferenczi, surgiria uma outra personalidade no inconsciente daquele que é submetido à educação dogmática (p. 41), que é bem diferente de outra cena, inconsciente freudiano, submetida a leis próprias. Também sua compreensão do recalque é alterada, na medida em que ele o toma apenas pela normatização social exagerada e não como algo basilar para a cultura e constitucional para o indivíduo.

Freud (1908/1992) atribui à moral sexual cultural o aumento da doença nervosa em seu tempo, mas distingue essa coerção nociva da vida sexual dos povos civilizados de um recalque necessário, que forma a base da vida em sociedade, pois a cultura se edifica sobre o sufocamento das pulsões. Sendo decorrente da renúncia pulsional necessária para a entrada na cultura, o sofrimento neurótico não é passível de amenização fácil. Enquanto Ferenczi se centra na mudança do registro inconsciente para a consciência, Freud discorre sobre o problema econômico gerado por essa renúncia pulsional inevitável para a vida em cultura.

\section{Mecanismos defensivos e adoecimento psíquico}

Para Ferenczi, tudo se inicia com a introjeção, responsável pela diferenciação entre prazer e desprazer, inaugurando o aparato psíquico. Mezan (1996, p.101) pontua que a introjeção para Ferenczi é uma espécie de abraço que o ego da criança faz com os objetos, num processo de investimento objetal que amplia o âmbito da nossa vida psíquica. Longe de ser um 
fenômeno isolado, na obra ferencziana, a introjeção é a própria forma de funcionamento do aparelho psíquico, implicando diretamente nas representações, identificações e produções de fantasia. Assim, a princípio, a introjeção aparece como o único mecanismo psíquico, até que, quando experimenta o desprazer imposto pelo objeto introjetado, a criança começa a não suportar o desprazer interno, projetando-o e fazendo com que a introjeção deixe de ser o único meio de que dispõe o psiquismo (Pinheiro, 1995, p.38). Cabe ressaltar que a introjeção também possui uma função defensiva peculiar, já que Ferenczi a ela atribui a produção de fantasias como defesas diante da castração e do desamparo, mas não funcionaria como um mecanismos de defesa diante do desprazer em si (Pinheiro, 1995, p.45). Costa (1995, p.13) pontua que assim como em Freud o Eros criava o aparato linguístico como defesa contra a pulsão de morte, as introjeções ferenczianas são a própria condição da existência do sujeito.

Entre outros mecanismos considerados por Ferenczi, está a regressão, tomada por ele como o próprio mecanismo da neurose, enquanto que para Freud, nesse contexto, ela seria considerada apenas como auxiliar ao próprio mecanismo do recalque. Além disso, Ferenczi não considera as três espécies de regressão apontadas por Freud: tópica, através do retorno da excitação que percorre os sistemas que compõem o aparelho psíquico, do préconsciente/consciência para o Inconsciente; temporal, remetendo o indivíduo a estruturas psíquicas mais antigas; e formal, designando a passagem a modos de expressão mais primitivos. As três se implicam mutuamente, a ponto de consistirem, no fundo, em apenas uma, pois o que é mais antigo no tempo é, em geral, mais primitivo na forma e está mais próximo do pólo perceptivo (Freud, 1900/1991, pp.541-2). Ao discorrer sobre regressão e expressões mais diretas do princípio do prazer sem mencionar o modo de funcionamento primário do aparelho psíquico, Ferenczi negligencia a lógica particular em vigor no sistema inconsciente.

Em $O$ problema da afirmação do desprazer, Ferenczi recorre ao texto freudiano $A$ Negativa (Freud, 1925/2007) para buscar superar o abismo que separa a vida pulsional da vida intelectual e reconsiderar o problema do sentido da realidade à luz das considerações freudianas. $\mathrm{O}$ autor localiza a negativa em um primeiro momento do reconhecimento do desprazer, no qual há uma tentativa de negá-lo, sendo depois necessário um esforço para negar essa negação.

Pinheiro (1995, p. 61) considera que, contrariamente ao recalcamento, que repele para o inconsciente as representações incompatíveis, para Ferenczi, as representações do trauma patológico são obrigadas a desaparecer sem deixar traços. Podemos concluir que a negativa na obra ferencziana se refere às percepções do mundo externo e para Freud ela é relativa ao conteúdo recalcado. Com a negativa, somente um dos resultados do processo de recalque é revertido: aquele que impede que o conteúdo da ideia alcance a consciência. Disso resulta, então, uma aceitação apenas intelectual do recalcado, o essencial do recalque permanece intocado (Freud, 1925/2007, pp.147-8). A autora afirma que Ferenczi acerta o alvo ao afirmar que o desmentido é o fator essencialmente traumático e desestruturante, contudo ele se perde na tentativa de justificá-lo, ao colocar de um lado a verdade e do outro a mentira (Pinheiro, 1995, p.74), não reconhecendo assim a ambiguidade simbólica.

Frequentemente Ferenczi se referiu a processos defensivos como sendo dirigidos ao mundo externo. Freud (1895/1992, p. 372), expõe a defesa normal como um mecanismo inibitório para evitar a descarga por uma via que libere desprazer e a defesa patológica é tida por ele como sendo referente à rememoração de algo que originalmente não seria objeto de desprazer 
e, por isso, não desencadearia defesa imediata, mas que adviria como uma percepção penosa, liberando desprazer e infiltrando o Eu de processos primários. A defesa que acarreta recusa da realidade, de uma percepção desprazerosa como a ausência de pênis na mulher, é a renegação, mas ela tem um custo muito alto: a cisão do eu (Freud, 1938/2007, p. 174). Embora afirme, tal como Freud, que o princípio do prazer permanece com força relativa ao longo da vida do indivíduo, Ferenczi não considera o reinado absoluto e irrestrito desse princípio no inconsciente, o que é fundamental para a clínica psicanalítica, já que são os produtos do inconsciente os principais objetos de análise.

\section{A técnica segundo Ferenczi}

No primeiro momento de sua obra, Ferenczi confia na efetividade do método analítico em entregar à sua destinação original as energias desviadas e desperdiçadas na produção e manutenção de sintomas mórbidos, afirmando que uma análise levada até o fim reforçaria as defesas do indivíduo, que não sucumbiria facilmente diante de novos traumas. Através da análise, seria possível adquirir um autoconhecimento completo, permitindo "neutralizar os complexos patogênicos, sob o controle permanente da consciência, submetendo-os às leis da razão lúcida" (1909a/2011, p. 60).

Isso também se aplica ao próprio analista, que deve buscar a autoanálise metódica para conseguir dominar com lucidez suas emoções e paixões para não quedar impotente diante de complexos de representações inconscientes carregados de afetos. Dessa forma, Ferenczi vê na descoberta de camadas mais profundas do psiquismo não somente a chave para a compreensão do princípio patológico das neuroses, mas também perspectivas ricas de esperança para a profilaxia (p. 61).

Em seus textos sobre a clínica, Ferenczi expõe sua compreensão das afecções psíquicas à luz de seus estudos sobre o desenvolvimento do eu, considerando a introjeção e a projeção responsáveis pela formação dos sintomas nas neuroses, os quais são determinados pela fixação no estágio introjetivo (estágios de onipotência, todas as experiências estão incluídas no eu) ou projetivo (estágio de realidade). A transferência também é considerada por ele como as introjeções que se manifestam no decorrer da análise e que visam a pessoa do médico, mas caberia à análise desmascarar o mais rapidamente possível essas relações fictícias, reconduzindo-as à sua verdadeira fonte (1909b/2011, pp.100-2).

Em 1919, é publicado o texto A técnica psicanalítica, que inicia discorrendo sobre resistências à associação livre, manifestas nos silêncios dos analisandos, nos "abusos da liberdade de associação" (quando passam a apresentar apenas material absurdo), além de "pôr em cena" seus conteúdos psíquicos ao invés de associar, tentar seduzir o analista. Embora afirmando que os analistas devem limitar-se a buscar as razões inconscientes sem, contudo, interferir em suas decisões e ações (pp.413-4), o autor defende que existem algumas circunstâncias nas quais o psicanalista poderia intervir diretamente na vida do paciente, por exemplo, quando adquire a convicção de que os interesses vitais dele exigem efetivamente uma decisão imediata que este ainda é incapaz de tomar sozinho. Em certos casos, o analista pode e deve praticar a "terapia ativa", induzindo o paciente a superar sua incapacidade para tomar uma decisão qualquer. Ele espera assim, graças às modificações dos investimentos afetivos que daí resultam, ter acesso ao material inconsciente até então inacessível (p. 414). 
A partir de então, são diversas as experimentações clínicas de Ferenczi, tais como a fixação de prazo para o fim do tratamento, análise de gestos e interdições de atos dentro e fora das sessões. Com a técnica ativa, Ferenczi considera que é possível ultrapassar os "pontos mortos" do trabalho analítico, intervindo ativamente em seus mecanismos psíquicos com o objetivo "de barrar as vias inconscientes e habituais de escoamento da excitação e de obter por coação o investimento pré-consciente, assim como a versão consciente do recalcado" (Ferenczi, 1919/2011, p. 7).

Ferenczi propõe uma técnica ativa, por considerar que a posição do analisando seguindo a associação livre é passiva. Ao desconsiderar esse esforço ativo do analisando em comunicar sem crítica o que lhe passa pela cabeça, de certa forma, o autor subestima o jogo dinâmico entre as forças do psiquismo, que faz com que seguir o fio das associações, falar e elaborar demande uma intensa labuta, na qual o conteúdo inconsciente busca se expressar e as forças recalcadoras que o enviaram para essa outra cena lutam para que ele lá permaneça.

Ele tenta solucionar o problema da economia da libido tratando o afeto como uma resistência, o qual, depois de descarregado através de alguma intervenção ativa, libertaria também o conteúdo recalcado no inconsciente. Embora afirme que na técnica ativa não haveria um direcionamento do analista acerca de para onde o afeto deveria ser reconduzido, ele usa expressões como "meta e objetos sexuais apropriados" (Ferenczi, 1919/2011, p. 6) e assegura que as forças pulsionais libidinais deixariam de sustentar os sintomas somente se fossem reconduzidas para os órgãos genitais. Ferenczi pensa que há certo objeto que pode receber o atributo de "apropriado" e que o direcionamento a ele é o que se espera ao fim de uma análise bem sucedida. Ao dividir a economia do psiquismo em "simples energias psíquicas" e "forças pulsionais genitais", Ferenczi (1919/2011, p. 8) demonstra grande equívoco no entendimento das pulsões, tratando-as como se houvesse uma energia em jogo no psiquismo que não é efeito de fontes corporais e que almeja satisfação e houvesse uma outra energia que está atrelada a um objeto e meta adequados, cujos desvios terão sintomas por consequência.

Na técnica ativa, trata-se menos de alcançar as fantasias e representações inconscientes do que de vencer a resistência. Não se passou muito tempo até que a fala do paciente fosse destituída de sua posição central do trabalho analítico. Ferenczi relata que, em casos de pessoas com uma atividade fantasística particularmente pobre, se viu coagido a provocar fantasias (1924/2011, p. 264). Assim, a recomendação que ele faz é que o analista tanto interdite algumas vias associativas, quanto proponha outras. De um jeito ou de outro, ele almeja "reencontrar o caminho dos objetos e das metas da sexualidade infantil outrora abandonados e preencher assim a condição básica de toda normalidade psicossexual" (p. 269). Dessa forma, tanto as interdições quando as fantasias provocadas objetivam retomar essa via da fantasia infantil que conduziria ao acesso a uma sexualidade normal. É importante ressaltar que a fantasia é um dos pontos remanescentes nos quais o princípio de prazer reina mesmo após a instauração do princípio de realidade, portanto, não é sem consequências a utilização da fantasia numa perspectiva adaptacionista.

O artigo O problema do fim da análise (Ferenczi, 1928c/2011) inicia com a exposição do caso de um paciente cuja patologia consiste precisamente na necessidade de mentir, o que configurava para o analista que a aplicação da regra fundamental talvez não tivesse a eficiência necessária em tal contexto. A expressão "mentira" tantas vezes repetida no texto adquire um sentido muito maior de intencionalidade do que de alheamento. Ferenczi chega 
mesmo a afirmar que "aquilo a que, segundo princípios da moral e da realidade, chamamos mentira, na criança e na patologia tem o nome de fantasia" (p. 19). No decorrer do tratamento, é papel do analista explorar tal estrutura fantasística, produzida automática e inconscientemente. Ferenczi considera que, embora tal procedimento de desvendamento da fantasia faça com que grande parte dos sintomas desapareça, a presença de resquícios de uma "realidade efetiva" remanescentes desse conteúdo fantasístico não tinham tanto relevo para a técnica até então. Ele alega ter aprendido com sua experiência clínica, no entanto, que é fundamental uma separação rigorosa entre o real e a fantasia para que a análise pudesse ser considerada concluída. Segundo ele, é possível dizer "que o neurótico não pode ser considerado curado enquanto não renunciar ao prazer do fantasiar inconsciente" (p. 19).

De certo modo, o autor caracteriza a mentira tomando por base os moldes de um mecanismo de defesa, pois a pessoa se sentiria forçada a mentir diante da ameaça de um desprazer ainda maior. Um dos maiores problemas advindos de tal posicionamento é a aproximação entre fantasia e mentira, conforme já foi exposto, e entre mentira, repressão e recalcamento.

Se na primeira tópica o inconsciente não teve para Ferenczi a mesma radicalidade que para Freud, isso não deixa de trazer consequências para sua compreensão da segunda tópica. $\mathrm{O}$ Isso seria a parte central da personalidade; o Eu, a parte periférica, que deve se adequar ao seu meio; e o Supereu seria o resultado de uma interação do eu com uma parte do meio ambiente (Ferenczi, 1928a/2011, pp.11-13). O que leva o autor a afirmar que o processo de cura consiste na possibilidade do paciente convocar o analista para ocupar o lugar do verdadeiro pai; muito embora depois venha a concluir que toda análise deveria pôr de lado, ao menos passageiramente, toda espécie de supereu, inclusive o do analista. Somente libertando o paciente de tais vínculos emocionais que transcendem a razão e as tendências libidinais, próprias do indivíduo, é que seria possível alcançar uma "cura radical", que consistiria numa espécie de desconstrução do supereu (Ferenczi, 1928b/2011, pp.39-40), ou, mais precisamente, da parte dessa instância que se tornou inconsciente. Do ponto de vista ferencziano, a análise deve ser uma verdadeira reeducação do paciente, pois nele se daria uma dissolução da estrutura cristalizada do caráter. Em outras palavras, o paciente "perderia" seu caráter e na análise aconteceria uma transição para uma estrutura mais "adequada", uma recristalização (1928c/2011, p. 21). Dessa forma, observa-se que Ferenczi propõe uma espécie de reeducação estrutural, que acarreta a ocorrência de diversas transformações radicais: separação nítida entre realidade factual e fantasia, desconstrução da parcela inconsciente do supereu e dissolução e reestruturação do caráter.

Para Ferenczi, em um indivíduo bem analisado, o recalque é apenas algo eventual, patológico e possivelmente desnecessário. $\mathrm{O}$ autor não percebe o recalque como estruturante não só do indivíduo, mas também da cultura, afirmando que "aprender a controlar-se nada tem a ver, evidentemente, com o recalcamento" (1928a/2011, p. 15). Conforme Freud (1930/1992) aponta, já incorporando à discussão a questão da agressividade oriunda da pulsão de morte, o recalcamento das pulsões forma a base da vida em sociedade. Sendo assim, a satisfação pulsional plena torna-se impossível a partir do momento que o homem ingressa na cultura. Mesmo que se alcance certa satisfação, haverá sempre um excedente pulsional que causa tensão no psiquismo e, diante desse desprazer, desencadeará um mecanismo de defesa. Esse excedente pulsional, impossível de ser amansado, é ainda mais intenso levando em 
consideração a pulsão de morte, que não pode ser sublimada e sempre demanda uma cota de descarga direta.

No último momento de sua obra, Ferenczi reflete sobre o fim de análise, que coincidiria não somente com a eliminação das resistências, mas também com uma "adaptação à realidade rica em frustrações" (1929/2011, p. 60). Nesse período, ele também liga a possibilidade de fim de análise à formação do analista, formulando o que ele chama de "segunda regra fundamental", que consiste na análise de todo aquele que queira ser analista (1928b/2011, p. 31).

Esses questionamentos autênticos foram louvados por Lacan por trazer para o debate a questão da responsabilidade do terapeuta. Para ele, Ferenczi foi "o autor da primeira geração a questionar com mais pertinência o que se exige da pessoa do analista, sobretudo quanto ao fim do tratamento" (Lacan, 1955/1998, p. 342). Comentando tais reflexões, Lacan extrai uma indicação para formular o que o analista deve vencer em sua análise: as mudanças técnicas de Ferenczi requerem que com sua análise o analista tenha aprendido a não "dar livre curso a seu narcisismo" (Bernardes, 2002, p.312). O apagamento do eu do analista não conduz, contudo, a uma prática asséptica, pois há um remanescente da equação pessoal: a questão do tato. Bernardes afirma que o tato implica para Ferenczi "numa capacidade de 'sentir com' (Einfühlung), traduzida por Lacan por 'conivência'. [...] Ferenczi insiste que esse Einfühlung deve aliar-se a uma apreciação consciente da situação, ditada pela experiência analítica" (Bernardes, 2002, p. 313).

Resumidamente, Lacan aponta os aspectos associados à posição do analista definidos por Ferenczi: "redução da equação pessoal; lugar segundo do saber; bondade sem complacência; influência que saiba não insistir; (...) em todas estas indicações, não é o eu que se apaga para dar lugar ao não-sujeito da interpretação?” (Lacan, 1955/1998, p. 343). Com essa pergunta, Lacan situa a problemática da falta-a-ser do analista dentro da crítica de uma visão dualista da relação entre analista e paciente. Assim, situando a falta-a-ser, único ser do analista, no coração da experiência analítica, Lacan coloca em tensão o que é da ordem do ser e o que é da ordem da função do analista (Bernardes, 2002, p. 314).

Ferenczi, nos anos seguintes ao seu texto concernente ao final de análise, seguiu investigando o tratamento do trauma, buscando nisso a descoberta de material inconsciente, mas também descarga energética. Segundo o autor, o choque traumático põe toda a atividade psíquica num estado de passividade desprovido de toda e qualquer resistência, uma comoção psíquica. A impressão do ocorrido não seria propriamente percebida e, sendo assim, não haveria defesa possível. Ele propõe, então, a repetição do próprio traumatismo em condições mais favoráveis, levá-lo, pela primeira vez, à percepção e à descarga motora (Ferenczi, 1934/2011, p. 129).

No momento final de sua técnica, em oposição ao aumento de tensão proposto com a atividade, Ferenczi busca o relaxamento, ou um balanceamento entre os dois princípios. Essa chamada neocatarse seria, para Ferenczi, muito distinta da catarse original por vir como um acréscimo aos avanços que a psicanálise teve até então, não reduzindo toda a técnica a isso. Além disso, apesar de haver uma descarga do afeto ligado àquele evento traumático, não necessariamente o paciente deixará de ser impelido à repetição A razão dessa revisitação está estreitamente ligada ao anseio de alcançar todo o material mnêmico traumático, pois somente assim a análise poderia ser considerada concluída para Ferenczi (1930/2011, p. 73). 
Em sua busca para lidar com a energia que estava ligada aos sintomas e ao trauma, Ferenczi passou por diversas técnicas, que mostraram êxitos provisórios e conduziram a novas descobertas, mesmo que a conclusão fosse apenas que não se deveria seguir por tal caminho. Reconhecendo as limitações da análise, os avanços técnicos de Freud foram muito mais cautelosos. O impossível de ultrapassar em uma análise foi tomado por Lacan como da ordem do real. Real este que o analista deve encarnar para que o trabalho do analisante não seja infinito (Bernardes, 2002, p. 315).

Por um lado, pode-se dizer que Ferenczi não percebeu que a resistência é sempre do analista, conclusão a que Lacan chegou posteriormente, confundindo por vezes a parte do analista na transferência com a implicação do sujeito do analista (Bernardes, 2002, p. 315). Por outro lado, Ferenczi demonstra que as regras técnicas estão longe de garantir um bom desenrolar do tratamento, podendo funcionar, inclusive, como uma defesa do analista (Pinheiro, 1995, p.108), que, hipocritamente, poderiam usar os conceitos como uma defesa para não se responsabilizarem pelo processo analítico (Ferenczi, 1928b/2011).

\section{Reflexões finais}

Desde o início de sua obra, Ferenczi teve uma preocupação com a profilaxia, abordando, inclusive, algumas vezes a questão da educação e da sociedade, retomando também diversas vezes o tema do esgotamento do inconsciente. Embora Freud sempre tenha tido uma postura crítica em relação à cultura - apontando pontos problemáticos que conduziam ao sofrimento psíquico -, ele sempre reconheceu as restrições ao livre fluxo das pulsões como condição intrínseca para a vida em sociedade, tornando impossível pensar numa profilaxia no que concerne a este ponto.

Ferenczi almeja alcançar até mesmo um fragmento de realidade factual por trás do recalcamento originário, que se relaciona com aquilo que está para sempre perdido. Já Freud, ao longo de sua experiência na clínica, reconheceu a muito custo que era inútil perseguir a realidade factual obstinadamente, pois tudo ao que temos acesso é realidade psíquica. A fantasia não pode ser descartada tal como se fosse uma mentira intencional, pois tem seu grande valor de derivado do inconsciente. Aliás, a própria mentira deliberada não escapa do determinismo psíquico.

Assim, enquanto Ferenczi busca a realidade factual, o abandono da mentira, a transformação da parcela inconsciente do supereu em consciente e, por fim, uma análise que acabe por esgotamento; Freud permanece firme no desvelamento do material inconsciente através da fala, reconhecendo os limites do próprio psiquismo à emergência desse conteúdo. As instâncias supereu e isso são reconhecidas no contexto analítico na relação que guardam com o Eu, na medida em que o sofrimento, os sintomas e as inibições estão ligados ao cerceamento e alterações nas funções do Eu. Longe de traçar como objetivo da análise a dissipação das peculiaridades do caráter humano, a busca de uma normalidade e a garantia de que a pessoa foi completamente analisada, Freud afirma que é objetivo da análise garantir ao $\mathrm{Eu}$ as melhores condições psicológicas possíveis para o exercício de suas funções.

Podemos concluir que a questão da defesa é fundamental para compreender aproximações e divergências teóricas e técnicas entre Freud e Ferenczi. O recalque, conceito cuja compreensão diferenciada ocasionou posturas na técnica bastante problemáticas, que 
conduziram Ferenczi a traçar objetivos para a análise impossíveis e a intervir de modo a despertar ainda mais resistências.

Mautner (1996, p.31) aponta que uma distinção de prioridades entre os dois influiu nas suas realizações: Ferenczi queria curar, enquanto Freud privilegiava a investigação do psiquismo. Embora reconheçamos que não há clínica sem pesquisa, também podemos considerar que a preocupação ferencziana com a cura foi o motor de suas principais contribuições, mas também o que levou a um destino fracassado tantas de suas técnicas. Instigado pela clínica a ficar em um constante movimento de mudança, Ferenczi reconhecia seus erros e buscava sempre avançar no sentido da cura.

\section{Referências}

Bernardes, A. C. (2002). A segunda regra fundamental: um comentário sobre o Ferenczi de Lacan. Ágora: Estudos em Teoria Psicanalítica, 5(2), 311-316. Recuperado de: https://dx.doi.org/10.1590/S1516-14982002000200007

Ferenczi, S. (2011). Psicanálise e Pedagogia. In S. Ferenczi, Psicanálise I (A. Cabral, trad., pp. 39-44). São Paulo: Editora WMF Martins Fontes. (Trabalho original publicado em 1908)

Ferenczi, S. (2011). A respeito das psiconeuroses. In S. Ferenczi, Psicanálise I (A. Cabral, trad., pp. 45-62). São Paulo: Editora WMF Martins Fontes. (Trabalho original publicado em 1909a)

Ferenczi, S. (2011). Transferência e introjeção. In S. Ferenczi, Psicanálise I (A. Cabral, trad., pp. 87124). São Paulo: Editora WMF Martins Fontes. (Trabalho original publicado em 1909b)

Ferenczi, S. (2011). Dificuldades técnicas na análise de uma histeria. In S. Ferenczi, Psicanálise III (A. Cabral, trad., pp. 1-8). São Paulo: Editora WMF Martins Fontes. (Trabalho original publicado em 1919)

Ferenczi, S. (2011). As fantasias provocadas. In S. Ferenczi, Psicanálise III (A. Cabral, trad., pp. 261270). São Paulo: Editora WMF Martins Fontes. (Trabalho original publicado em 1924)

Ferenczi, S. (2011). A adaptação da família à criança. In S. Ferenczi, Psicanálise IV (A. Cabral, trad., pp. 1-16). São Paulo: Editora WMF Martins Fontes. (Trabalho original publicado em 1928a)

Ferenczi, S. (2011). Elasticidade da técnica psicanalítica. In S. Ferenczi, Psicanálise IV (A. Cabral, trad., pp. 29-42). São Paulo: Editora WMF Martins Fontes. (Trabalho original publicado em 1928b)

Ferenczi, S. (2011). O Problema do Fim da Análise. In S. Ferenczi, Psicanálise IV (A. Cabral, trad., pp. 17-28). São Paulo: Editora WMF Martins Fontes. (Trabalho original publicado em 1928c)

Ferenczi, S. (2011). A criança mal acolhida e sua pulsão de morte. In S. Ferenczi, Psicanálise IV (A. Cabral, trad., pp. 55-60). São Paulo: Editora WMF Martins Fontes. (Trabalho original publicado em 1929)

Ferenczi, S. (1930/2011). Princípio de relaxamento e neocatarse. In S. Ferenczi, Psicanálise IV (A. Cabral, trad., pp. 61-78). São Paulo: Editora WMF Martins Fontes. (Trabalho original publicado em 1930)

Ferenczi, S. (2011). Reflexões Sobre o Trauma. In S. Ferenczi, Psicanálise IV (A. Cabral, trad., pp. 125-135). São Paulo: Editora WMF Martins Fontes. (Trabalho original publicado em 1934)

Freud, S. (1992). Proyecto de psicología. In S. Freud, Obras Completas (J. L. Etcheverry, trad., Vol. 1, pp. 323-446). Buenos Aires: Amorrortu editores. (Trabalho original escrito em 1895 e publicado em 1950) 
Freud, S. (1991). La interpretación de los sueños. In S. Freud, Obras Completas (J. L. Etcheverry, trad., Vol. 4-5, pp. 1-612). Buenos Aires: Amorrortu editores. (Trabalho original publicado em 1900)

Freud, S. (1992). La moral sexual "cultural" y la nerviosidad moderna. In S. Freud, Obras Completas (J. L. Etcheverry, trad., Vol. 9, pp. 159-182). Buenos Aires: Amorrortu editores. (Trabalho original publicado em 1908)

Freud, S. (2007). A Negativa. In S. Freud, Escritos sobre a psicologia do inconsciente (L. A. Hanns, trad., Vol. 3, pp. 145-157). Rio de Janeiro: Imago Ed. (Trabalho original publicado em 1925)

Freud, S. (1930/1992). El malestar en la cultura. In S. Freud, Obras Completas (J. L. Etcheverry, trad., Vol. 21, pp. 57-140). Buenos Aires: Amorrortu editores. (Trabalho original publicado em 1930)

Freud, S. (2007). A Cisão do Eu no Processo de Defesa. In S. Freud, Escritos sobre a psicologia do inconsciente (L. A. Hanns, trad., Vol. 3, pp. 171-179). Rio de Janeiro: Imago Ed. (Trabalho original publicado em 1938)

Lacan, J. (1998). Variantes do tratamento padrão. In J. Lacan, Escritos (V. Ribeiro, trad., pp. 325364), Rio de Janeiro, Jorge Zahar. (Trabalho original publicado em 1955)

Mautner, A. V. (1996). Ferenczi: cultura e história. In: Katz, C. H. (Org.). Ferenczi: história, teoria, técnica (pp.15-42). São Paulo: Editora 34.

Mezan, R. (1996). O símbolo e o objeto em Ferenczi. In: Katz, C. H. (Org.). Ferenczi: história, teoria, técnica (pp. 91-120). São Paulo: Editora 34.

Pinheiro, T. (1995). Ferenczi: do grito à palavra. Rio de Janeiro: Jorge Zahar Ed.; Ed. UFRJ.

Roudinesco, E., Plon, M. (1998). Dicionário de Psicanálise (V. Ribeiro, L. Magalhães, trad.). Rio de Janeiro: Jorge Zahar Ed.

Recebido em março/2018 - Aceito em janeiro/2019. 